\title{
Localised corneal haze and scarring following pulsed accelerated collagen cross-linking for keratoconus
}

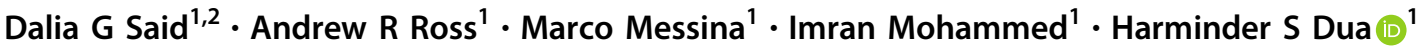

Received: 3 February 2018 / Revised: 13 July 2018 / Accepted: 22 August 2018 / Published online: 24 September 2018

(c) The Royal College of Ophthalmologists 2018

Corneal collagen cross-linking (CXL) is the only treatment that delays or arrests progression of keratoconus. CXL is a safe procedure with few complications. CXL protocols vary depending on time and energy used but all are safe and effective. Variations from the original Dresden protocol are based on the Bunsen-Roscoe law (BRL) [1], which states that "a certain biological effect is directly proportional to the total energy dose irrespective of the administered regime". [2] This implies that higher energy applied over short duration will have the same biological effect as lower energy applied over longer duration [1].

Forty-nine patients with progressive keratoconus had (epithelium-off) accelerated CXL with the Avedro $\mathrm{KXL}^{\circledR}$ system. All patients had 10 min of $0.1 \%$ riboflavin soak (1 drop every $2 \mathrm{~min}$ ). Twenty-one patients had CXL with 8minute pulsed protocol (1 sec on/1 sec off) with irradiation of $30 \mathrm{~mW} / \mathrm{cm}^{2}$ (group 1). Twenty-eight patients had 12minute continuous irradiation with $10 \mathrm{~mW} / \mathrm{cm}^{2}$ (group 2). Both groups had total energy of $7.20 \mathrm{~J} / \mathrm{cm}^{2}$.

We compared complications between the 2 groups and analysed these to pre-operative parameters (age, sex, maximum $\mathrm{K}, \mathrm{K} 1, \mathrm{~K} 2$, mean keratometry, corneal pachymetry at the thinnest location, cylinder and spherical equivalent) to determine any statistically significant correlation. Four patients from group 1 developed localised haze of which 2 were associated with an epithelial defect (Fig. 1). All four had persistent residual scar which led to initial drop of best corrected visual acuity (BCVA) but returned to baseline at

Harminder S Dua

harminder.dua@nottingham.ac.uk

1 Academic Ophthalmology, Division of Clinical Neuroscience, University of Nottingham, Nottingham, UK

2 Research Institute of Ophthalmology, Cairo, Egypt six months. There was no statistically significant difference between pre-operative parameters of these patients and the rest of patients in the group. Similarly, there was no statistically significant difference in pre-operative parameters between groups 1 and 2 (Table 1). The depth of the demarcation line also did not show a difference in the two groups.

Accelerated pulsed protocol used in this study was associated with severe localised corneal haze and residual scarring in $19 \%$ patients suggesting that it is not as safe as other accelerated protocols. Literature on the safety of this protocol is sparse [3]. Merwald et al. explained that exposure to pulsed UVA, particularly when used over short intervals, was associated with higher tissue damage compared to continuous delivery [4]. The demarcation line was found to be significantly deeper for patients treated with pulsed versus continuous same dose $\left(7.2 \mathrm{~J} / \mathrm{cm}^{2}\right)$ accelerated protocol indicating deeper penetration of energy with the former [5]. In a review on the reciprocity rule in photobiology, Schindl et al. have stated that biological tissues respond to electromagnetic radiation with a series of interacting events that render a time-dose relationship unlikely. The effect on the tissue is the cumulative result of the radiation and the agent used for photosensitizing compounded by the tissue response. Hence, the BRL would be applicable to biological tissues only within defined limits [2]. It is likely that the accelerated protocol we used falls outside these limits [1].

\section{Compliance with ethical standards}

Conflict of interest The authors declare that they have no conflict of interest. 
Fig. 1 a Patient 1, post-operative dense ill-defined central corneal haze. BCVA decreased by 4 lines (from 6/7.5 to 6/24) at 1 week post-operative. b A much fainter central scar remained with improvement of BCVA to $6 / 6$ at 6 months postoperative in the same eye. c Patient 2, post-operative dense well defined para-central corneal haze. d Epithelial defect corresponding to the area of the haze as seen by fluorescein $1 \%$ staining. BCVA decreased by 2 lines (from 6/9 to 6/18) at 1 week post-operative. e A very faint corneal scar remained at 5 months follow-up. BCVA improved to $6 / 9$

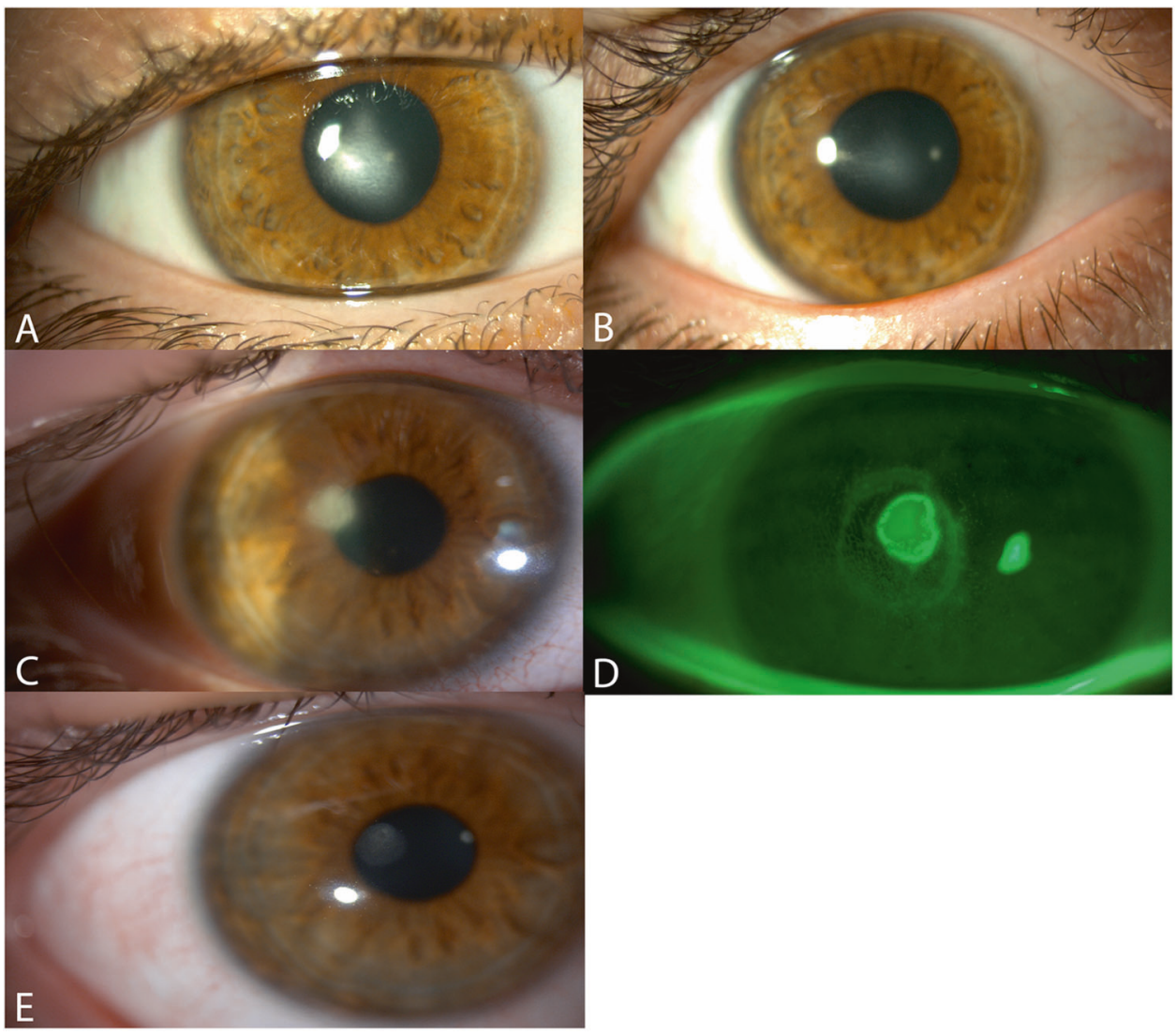

Table 1 Intra-group (patients with haze and those with no haze in group 1) and inter-group (between groups 1 and 2) comparison of pre-operative parameters

\begin{tabular}{|c|c|c|c|c|c|c|c|c|c|c|}
\hline & $\begin{array}{l}\text { Patients with } \\
\text { corneal haze }\end{array}$ & $\begin{array}{l}\text { Patients without } \\
\text { corneal haze }\end{array}$ & $\begin{array}{l}\text { Mean difference between patients } \\
\text { with and without haze }\end{array}$ & $\begin{array}{l}P- \\
\text { value }\end{array}$ & $\begin{array}{l}95 \% \text { confidence } \\
\text { interval }\end{array}$ & Group 1 & Group 2 & $\begin{array}{l}\text { Mean difference between } \\
\text { group } 1 \text { and } 2\end{array}$ & $\begin{array}{l}P- \\
\text { value }\end{array}$ & $\begin{array}{l}95 \% \text { confidence } \\
\text { interval }\end{array}$ \\
\hline $\mathrm{K} 1$ & $46.27 \pm 6.25$ & $47.22 \pm 4.97$ & $0.95 \pm 2.89$ & 0.746 & -5.01 to 6.99 & $\begin{array}{l}47.04 \pm \\
5.08\end{array}$ & $\begin{array}{l}47.38 \pm \\
3.73\end{array}$ & $-0.33 \pm 1.25$ & 0.793 & -2.86 to 2.19 \\
\hline $\mathrm{K} 2$ & $48.55 \pm 5.98$ & $51.38 \pm 4.58$ & $2.83 \pm 2.68$ & 0.304 & -2.78 to 8.45 & $\begin{array}{l}50.84 \pm \\
4.84\end{array}$ & $\begin{array}{l}50.62 \pm \\
4.32\end{array}$ & $0.22 \pm 1.31$ & 0.865 & -2.41 to 2.86 \\
\hline $\mathrm{Km}$ & $47.35 \pm 6.11$ & $49.18 \pm 4.68$ & $1.84 \pm 2.74$ & 0.510 & -3.90 to 7.58 & $\begin{array}{l}48.84 \pm \\
4.87\end{array}$ & $\begin{array}{l}49 \pm \\
3.78\end{array}$ & $-0.16 \pm 1.23$ & 0.894 & -2.64 to 2.31 \\
\hline $\mathrm{Kmax}$ & $54.92 \pm 8.67$ & $60.58 \pm 6.99$ & $5.66 \pm 4.05$ & 0.178 & -2.82 to 14.14 & $\begin{array}{l}59.51 \pm \\
7.46\end{array}$ & $\begin{array}{l}58.73 \pm \\
6.4\end{array}$ & $0.78 \pm 1.98$ & 0.695 & -3.21 to 4.77 \\
\hline $\begin{array}{l}\text { Corneal pachymetry at the } \\
\text { thinnest location }\end{array}$ & $465.5 \pm 36.75$ & $440.3 \pm 40.18$ & $-25.21 \pm 22.04$ & 0.267 & -71.33 to 20.92 & $\begin{array}{l}445.1 \pm \\
39.96\end{array}$ & $\begin{array}{l}449.3 \pm \\
30.86\end{array}$ & $-4.22 \pm 10.11$ & 0.678 & -24.57 to 16.11 \\
\hline Cylinder & $-2.92 \pm 1.46$ & $-4.40 \pm 2.15$ & $-1.48 \pm 1.31$ & 0.271 & -4.22 to 1.26 & $\begin{array}{l}-4.17 \pm \\
2.09\end{array}$ & $\begin{array}{l}-3.22 \pm \\
1.65\end{array}$ & $-0.94 \pm 0.58$ & 0.115 & -2.14 to 0.24 \\
\hline Spherical equivalent & $-1.12 \pm 3.19$ & $-0.92 \pm 0.09$ & $0.21 \pm 1.66$ & 0.902 & -3.28 to 3.70 & $\begin{array}{l}-0.94 \pm \\
2.59\end{array}$ & $\begin{array}{l}-1.61 \pm \\
3.79\end{array}$ & $0.65 \pm 0.92$ & 0.482 & -1.20 to 2.51 \\
\hline
\end{tabular}

\pm standard deviation

\section{References}

1. Shajari M, Kolb CM, Agha B, Steinwender G, Müller M, Herrmann $\mathrm{E}$, et al. Comparison of standard and accelerated corneal cross-linking for the treatment of keratoconus: a meta-analysis. Acta Ophthalmol 2018; epub ahead of print 31 May 2018; https://doi.org/10.1111/aos. 13814

2. Schindl A, Rosado-Schlosser B, Trautinger F. Reciprocity regulation in photobiology. Overv Hautarzt. 2001;52:779-85.

3. Mazzotta C, Traversi C, Caragiuli S, Rechichi M. Pulsed vs continuous light accelerated corneal collagen crosslinking: in vivo qualitative investigation by confocal microscopy and corneal OCT. Eye (Lond). 2014;28:1179-83.

4. Merwald H, Klosner G, Kokesch C, Der-Petrossian M, Hönigsmann $\mathrm{H}$, Trautinger $\mathrm{F}$. UVA-induced oxidative damage and cytotoxicity depend on the mode of exposure. J Photochem Photobiol B. 2005;79:197-207.

5. Peyman A, Nouralishahi A, Hafezi F, Kling S, Peyman M. Stromal demarcation line in pulsed versus continuous light accelerated corneal cross-linking for keratoconus. J Refract Surg. 2016;32:206-8. 